\title{
Um teatro novo? \\ Sobre o projecto de António Ferro
}

\section{Rita Duarte Correia}

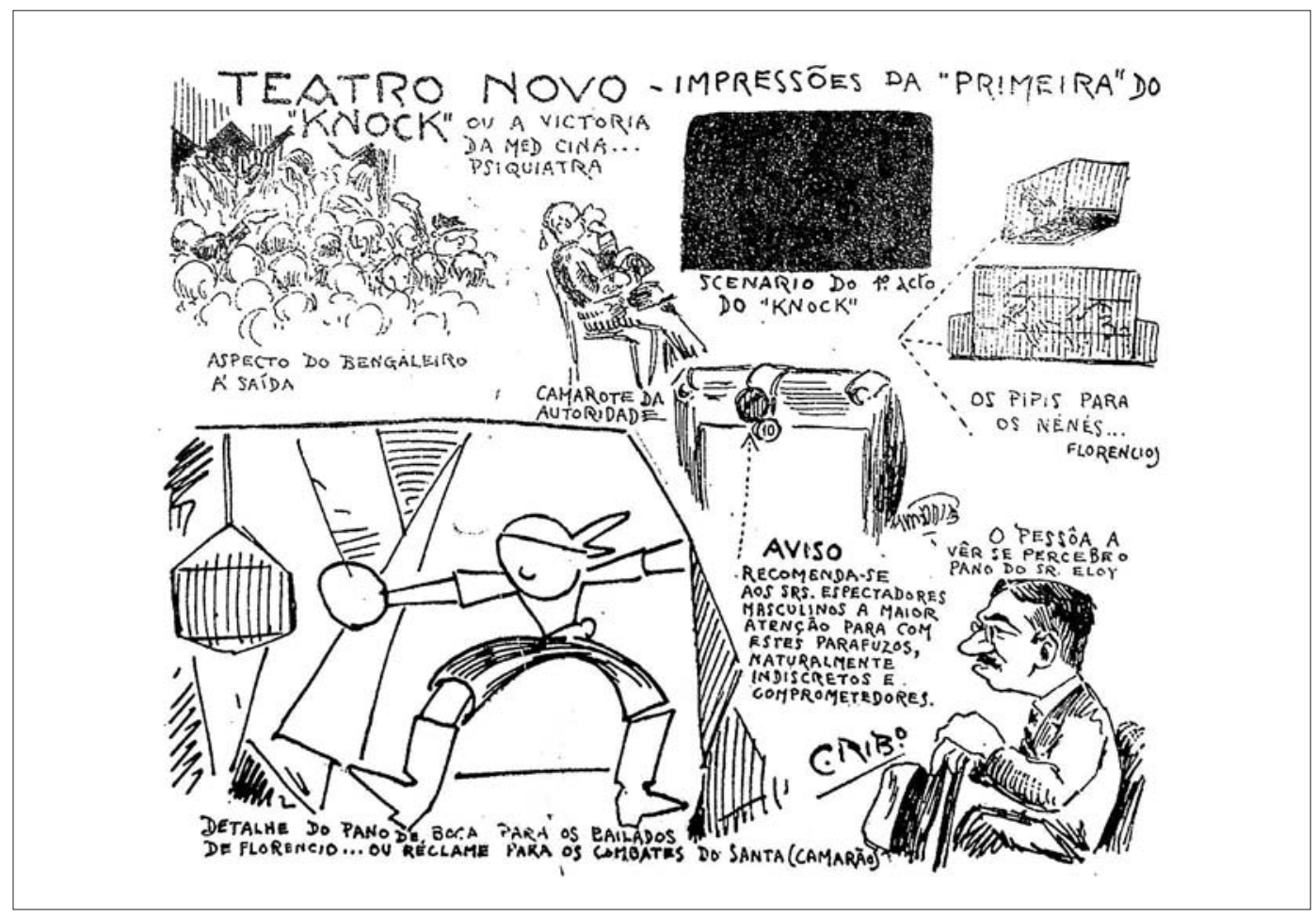

Situando-se numa estreita fatia temporal (o primeiro semestre de 1925), o "projecto" do Teatro Novo, tendo por principal mentor António Ferro, confrontou-se com vicissitudes e tensões próprias do pós-guerra e reflecte os múltiplos e contrastantes diálogos estéticos europeus, com inequívocos reflexos entre nós. Os anos vinte foram, de facto, conturbados internacionalmente, facto que reverteu em tensões políticas para Portugal, bem visiveis num desfilar de sucessivos governos que, ciclicamente, caíam e voltavam ao poder. As vicissitudes do advento da República portuguesa estavam ainda bem presentes na memória de todos; o sistema político dava pequenos passos na tentativa de afirmação e de consolidação, tarefa dificultada pelas conjunturas de mutações económicas e sociais verificadas também a nível internacional.

Simultaneamente, um fervilhar de ideias desejoso de romper com cânones sócio-culturais e fazer florescer criações realmente inovadoras emanava do espírito dos jovens intelectuais. A dependência de Portugal relativamente aos ditames e determinações europeias de carácter estético, sendo uma evidência que já não é de hoje, verificar-se-ia nesta fase da nossa História através de importantes vectores de entre os quais se destacam: por um lado, a música e, por outro lado, o bailado. Musicalmente, as últimas décadas do século XIX e o início do século XX ficaram marcados a nivel europeu por grandes assimetrias, mutações, revoluções criadoras de cultos epigonais e de charneira, entre um romantismo tardio, um verismo acentuado e um prenúncio de vanguardas. De inspiração verista, encontramos Antonín Dvorák e Leós Janacék, Smetana ou Tchaikovsky. No que diz respeito ao impressionismo, seria Claude Debussy quem se evidenciaria pelo desenvolvimento dessa linguagem no campo musical, aproximando-se do gosto decadente da literatura europeia sua contemporânea. Já nos anos vinte, a cíclica reutilização de doze notas, preconizada pelo movimento do dodecafonismo, criado e empreendido por Arnold Schönberg, Alban Berg e Anton Weber (da Primeira Escola de Viena), viria a acarretar rupturas com o sistema tonal. Estas inspirações musicais teriam os necessários reflexos na composição portuguesa, através de insignes da nossa música como Vianna da Mota, Luís de Freitas Branco, David de Sousa ou Francisco de Lacerda, entre outros.

Quanto ao bailado e, mais especificamente, à afirmação do Ballet Russe, este estabeleceu-se como o prenúncio do fim da aventura romântica mediante a crise do bailado 


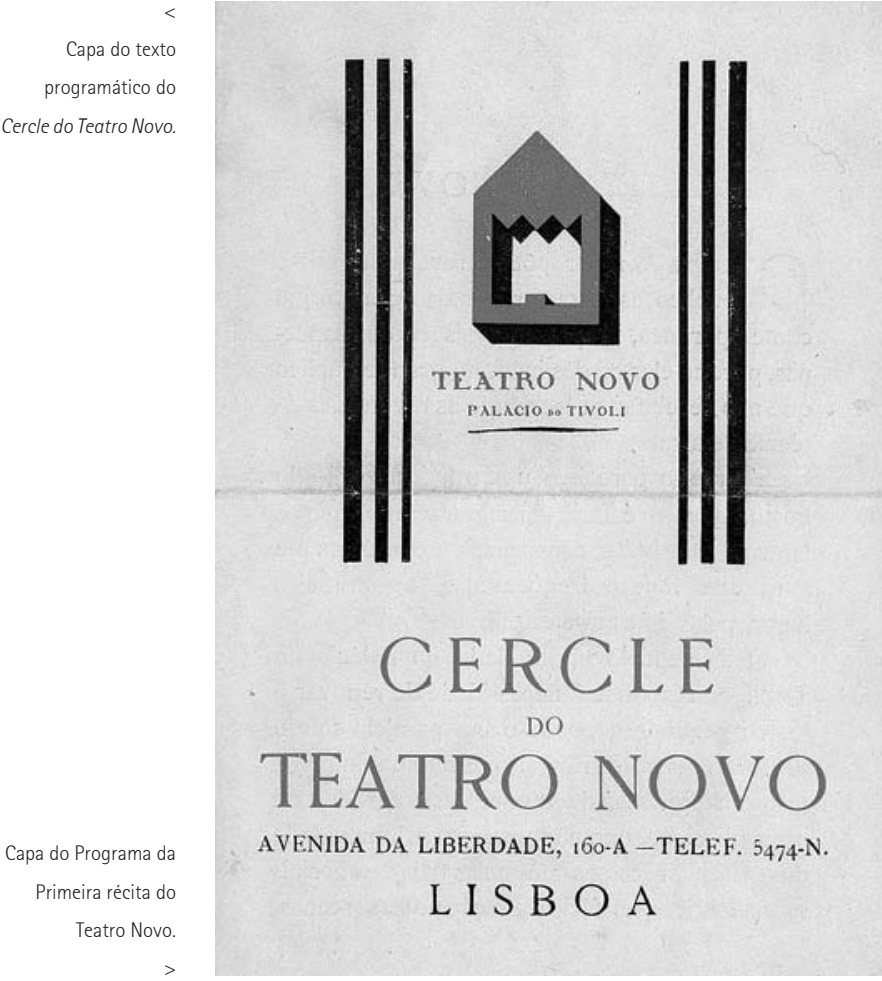

europeu, onde se assistia a um esgotamento quer a nive da estereotipação de cenários, quer no que diz respeito à inexistência de inovações em libretos e guarda-roupa. Os Ballets Russes passariam por Portugal com Nijinski e Diaghilev. Com eles passaram, junto de certa

intelectualidade, os ventos de mudança que a inovação estética dos Ballets propunha. No ano de 1917, a revista Portugal futurista, no artigo "Os Ballets Russes em Lisboa", assinado por Almada-Negreiros, Ruy Coelho e José Pacheko, assinalava a importância desse acontecimento cultural.

Outros incontornáveis marcos para a contextualização cultural e estética dos anos vinte portugueses são as influências exercidas pelos movimentos de vanguarda no nosso país, nomeadamente o Modernismo e o Simbolismo, assim como a experiência que o teatro Naturalista francês - sobretudo o Théâtre Libre de Antoine - viria a inspirar na projecção do Teatro Novo.

Quanto a este projecto, o que mais importa dizer sobre ele relaciona-se com as polémicas em que se encontrou envolvido, muito antes de a primeira peça - Knock, de Jules Romains - ter sido levada à cena. Com efeito, nascendo envolvido em polémica, e tendo apresentado poucos espectáculos, originaria uma controvérsia quase fulanizada, pelo que o seu percurso viria a esbater-se súbita e inexplicavelmente. Subjaz, porém, uma questionação em torno do que terá definido, enfim, o projecto do Cercle do Teatro Novo. Um momento de inquietação, um assomo ou um epifenómeno, que se viu revestido de inquestionável valorização por ter levado avante tentativas de repercutir tendências estéticas europeias em território nacional, acabando, apesar disso por se reverter numa fugaz e efémera experiência. Terá sido, por isso, um episódio cuja duração não completou um mês e que, por várias e longas semanas, se encontrou envolto em polémicas que resistiram heroicamente até ao produto representado. Por seu turno, estas controvérsias desempenharam, consequentemente, o papel de autênticos

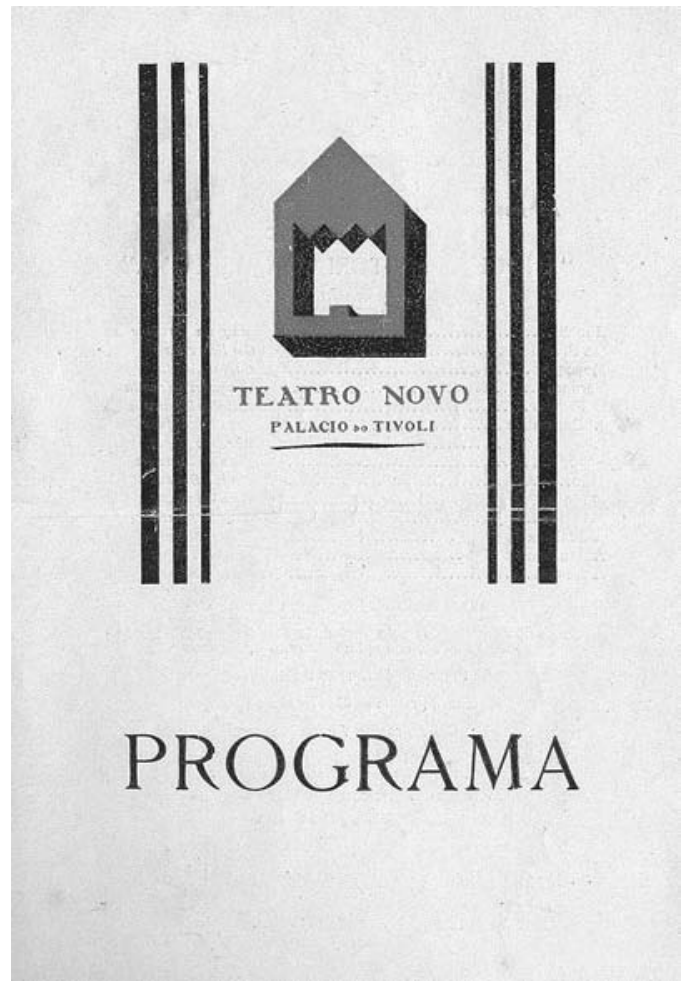

satélites gravitacionais alheios à real importância que os criadores do Teatro Novo Ihe queriam conferir. As polémicas terão coadjuvado, de alguma forma, a que se retirasse parte da energia e da vitalidade essenciais para uma apreciação cabal e imparcial do verdadeiro trabalho de renovação a que se propunha.

Tendo por mentores intelectuais como Ferro, José Pacheko e Lino Ferreira, pretendia-se que as mutações artísticas, a efervescência política e cultural a que se assistia na Europa fossem visiveis neste projecto. Sendo, todavia, prematuro e incipiente, sobretudo pelos artistas de que se fez rodear, o Cercle poderá ter funcionado como ensaio ou esboço daquilo que Ferro viria a colocar em prática com o Teatro do Povo (1936) e os Bailados do Verde-Gaio (1940) - estas iniciativas, nestes anos, terão sido, portanto, implementadas já de forma cimentada e madura, bem assimiladas as várias tendências estéticas e, sobretudo, com um António Ferro devidamente protegido pelo Regime Estadonovista). Quando se alude a uma certa incipiência do Cercle abre-se espaço para serem levantadas, por exemplo, questões episódicas da própria encenação do Teatro Novo. Joaquim de Oliveira, numa obra publicada em 1950 sobre as suas memórias do Teatro Novo, escreve, a determinada altura e a propósito do convite que lhe fora dirigido para encenar a primeira peça colocada em cena pelo Cercle, que guardara uma enorme mágoa sobre esta encenação: ao observar o cenário imaginado por Leitão de Barros, deparara-se com uma "cópia infeliz do cenário que se percebia do borrão das capas da Petite Illustration. Acrescentava, não obstante, que este cenário, por tentar colocar em prática a novidade do panorama em movimento (uma inovação técnica), se tornava impraticável pelo excesso de ruido que produzia, o que seria comprometedor da ideia e do próprio António Ferro. A partir deste exemplo poderemos imaginar o restante aparato cénico e a filosofia subjacentes à colocação em cena da peça de Jules Romains. Por isso mesmo, do 
conjunto documental apresentado sobre o Teatro Novo, poder-se-á inferir que esta novidade não terá sido muito mais do que um conjunto de bravatas pessoais transformadas numa excelente rampa de lançamento para outros interesses e outros projectos de António Ferro.

\section{Teatro Novo. 0 que pensam a tal respeito Carlos Malheiro Dias, Júlio Dantas e Henrique Lopes de Mendonça'}

Eis o que nos disse Carlos Malheiro Dias antes de partir para o Brasil:

Todas as iniciativas que combatam a rotina, que the dêem uma guerra sem quartel, merecem o meu aplauso. 0 Teatro Novo é uma bela consequência da actividade de meia dúzia de rapazes. 0 Teatro Novo pode ser um passo para a frente na nossa civilização. Combatê-lo não é apenas um erro: é um crime.

0 depoimento de Júlio Dantas:

"Teatro Novo"? Mas entendamo-nos. Novo em quê? Na data? Na idade dos autores? Nas ideias? Nos processos? É o teatro que dá as "últimas novidades"? É o teatro que representa as peças dos "novos"? É o teatro que se propõe discutir as ideias e os problemas do momento? É o teatro simplesmente novo no processo de realização cénica, cubista, futurista, expressionista? Não sei. Para representar as últimas novidades, a salinha do Tivoli não chega: não se mete o mundo numa bombonnière. Para só representar peças de rapazes novos - seria necessário não deixar entrar os cabelos brancos de Pirandello. Representar as obras doutrinárias, fazer o teatro-tribuna, não vale a pena: ninguém vai ao teatro para ler artigos-de-fundo nem para ouvir sermões. Resta a hipótese do teatro de processos novos. É uma curiosidade, mas uma curiosidade "efémera". Entretanto, não deixaria de ser interessante - confesso - assistir amanhã à representação de uma peça como a do jovem Bertolt Brecht, Rufo dum tambor na noite, com a realização cubista que the deu o Kammerspiele, de Munique. Eu gosto do cubismo. Gosto de tudo o que me diverte. Mas para mim - sinceramente Iho digo - não há "teatro novo" nem "teatro velho". As obras de arte não têm idade. 0 que há é "teatro bom" e "teatro mau" _ teatro que atrai e teatro que repele. Põem o primeiro? É um sucesso. Põem o segundo? É um desastre. E aqui tem a minha opinião, que, como vê, não tem interesse nenhum.

A opinião de Henrique Lopes de Mendonça:

Só algum tacanho rabugento negará a sua simpatia à tentativa do Teatro Novo. Por mim, posto que aleitado às tetas do Romantismo, nunca me mostrei desfavorável a quaisquer experiências inovadoras, e até tive durante a minha vida literária ocasião de lamentar a falta de palco onde elas se realizassem. Com um fruto da minha lavra sucedeu uma vez ter ele, com o decorrer do tempo, perdido o sabor acre das primícias e quando alcançou a dita de ser exposto à guloseima pública, já o sol da moda o sazonara talvez em demasia. Para que outro tanto não possa repetir-se com os meus jovens colegas, deve animarse o empreendimento, embora sem indagar com demasiada circunspecção até que ponto ele é viável no nosso meio. Deixemos à juventude os méritos da temeridade. Não Ihe faltará com o seu amparo a Fortuna, de harmonia com o clássico ditame.

Porque a primeira condição de empreendimentos desta natureza é a estóica abstenção de lucros materiais. Desde que se mercantilizam, começam a atraiçoar a sua missão. Passam a ser objecto de exploração banal, e quantas vezes corruptora, dos empresários de ofício. Só a generosidade algo imprevidente da mocidade os pode manter na elevada esfera que lhes é adequada, não se limitando a exibir o ultra-moderno, mas desenterrando e desempoeirando tanta velharia a que o sol de hoje presta cores de novidade. Convençamo-nos de que Ibsen ou Sudermann, Pirandello ou Bernardo Shaw não são mais estranhos e curiosos para os homens actuais do que Aristófanes ou Kalidasa, Marlowe ou Calderon de la Barca, e até o nosso Gil Vicente do Velho da Horta e de Rubena. Em arte, afinal de contas, assistimos constantemente ao seguinte espectáculo: a dentuça do futurismo aferrando pela ponta a cauda revolta da tradição.

\section{Teatro Novo. 0 que pensam a respeito desta iniciativa Ramada Curto, Vitoriano Braga e Gualdino Gomes $^{2}$}

Eis o depoimento do sr. Dr. Ramada Curto:

0 Teatro Novo é uma ideia altamente simpática. Se os nossos dramaturgos tiverem que dizer ao público coisas "novas", que não caibam nos palcos "velhos", já se não podem queixar de não terem lugar onde dizê-las. Teatro já há. Faltam agora os Pirandello, os Shaw, os Curel e os Lenormand. Existem? É o que o Teatro Novo vai procurar demonstrar. De resto, se não existirem, a culpa não é dos fundadores da boitte e fica-Ihes a consolação de que nestas coisas de arte, como em tudo, não há apostolados inúteis.

Quando não salvam mais ninguém salvam os apóstolos.

0 sr. Vitoriano Braga diz-nos, sem relutância alguma, o que se segue:

Não creio, e com que mágoa o digo, no êxito do Teatro Novo, ideia que o meu espírito aplaude em absoluto e na qual há dez anos penso. Contudo, duvido do seu êxito porque sei a guerra que Ihe vai ser movida pelos autores. De uma maneira geral o actor não tem interesse em interpretar peças cuja representação não seja "finalidade". Se o valor da obra a representar é tão grande que o principal interesse reside no valor intelectual da obra e a representação é simplesmente um "meio" de patentear esse valor, o actor sente-se reduzido, amesquinhado e
Diário de Notícias, 21 de Abril de 1925.

2 Diário de Notícias, 26 de Abril de 1925. 
Capa da primeira ediçãa

de Mar alto,

de António Ferro

(Portugália Editora, 1924) combate a representação desse género de peça de teatro superior. Tem razão? Talvez. Quem escreveria verdadeiramente peças de teatro: Ibsen ou Sardou? Para o caso presente o que importa é que pretendendo, certamente, os organizadores do Teatro Novo montar peças de primeira categoria, isto é, o teatro em que a representação é meio, o artista ou se desinteressa pela razão exposta ou confessa tacitamente que as peças a que deve a sua notoriedade não são, não podem ser consideradas de arte absoluta.

Apesar do que aqui fica dito, que mais é um desabafo, o Teatro Novo e os seus organizadores contam absolutamente comigo. Gualdino Gomes é breve:

- Sim, meu caro amigo, Teatro Novo; mas novo em tudo: no edifício, nas peças, nos cómicos, e até no público. Novo... como aquela prosa que ainda não havia no tempo de Fradique Mendes.

\section{Má-língua: Fantasia cénica, levemente cínica e muito sónica ${ }^{3}$ \\ (Argumento)}

Novo Teatro. - Magia em um acto ou dois ou mesmo mais se for preciso.

(Foi à cena na Bica do Sapato

às zero horas do dia de juízo.)

Personagens: um cego, um visionário, um biombo, um jornalista, uma cadeira, três ou quatro fragmentos de empresário, e cinco peças de serapilheira.

Cenário: Uma saleta na Avenida toda pintada de oca e alvaiade; janelas para um beco sem saída; portas que chiam muito.

\section{- Actualidade. -}

Assim que entra o primeiro espectador ouvem-se as três pancadas de Molière, vindo à boca de cena um director talhar a canivete uma colher

Se depois do primeiro entrar segundo o cego põe o bumbo no proscénio vem logo o jornalista pelo fundo bate no bumbo e diz: "Eu sou um génio."

Todos aplaudem calorosamente e ele repete: "Um génio!" - erguendo um dedo. Do céu, (aos trambolhões) cai Gil Vicente que vem mamando um limãozinho azedo.
$\begin{array}{lllllllllllll}A & N & T & O & N & \text { I } & O & \text { F } & \text { E } & R & R & 0\end{array}$ MAR ALTO PEÇa EM 5 agrogs PREFACIO EO AUTOB/ 4 .

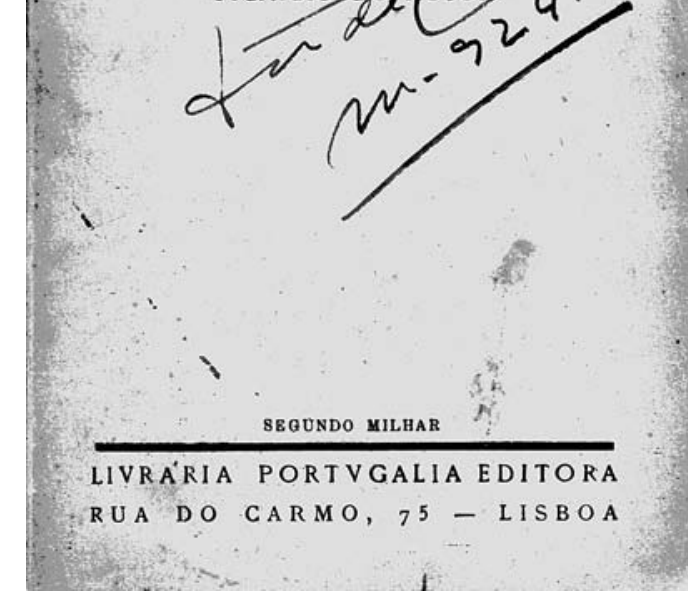

Montado numa cana, o visionário vem a correr mandar cantar o cego e pega nos fragmentos de empresário, que vai, à esquerda baixa, pôr num prego.

As cinco peças de serapilheira desenrolam-se então com majestade indo formar em torno da cadeira um halo circular de divindade.

$\mathrm{Na}$ cadeira se senta o jornalista que, vendo Mestre Gil aos trambolhões, Ihe acalma o frenesi malabarista dizendo apenas: "Toma lá pinhões..." -

Nesta altura, entusiasmo delirante. Avança um dirigivel de oxigénio no qual o jornalista, num rompante se instala repetindo: "Eu sou um génio."

A seguir há uma ceia de homenagem. (Ouve-se ao longe um relinchar de potros) Reina o box; há knock-out sob a linhagem. Ficam todos a olhar uns para os outros.

Cada um diz o que the vem à Ideia. E quem a não tiver, com um abano põe-se a abanar uma fornalha cheia de terra, cinza e nada.

- Cai o Pano. - 


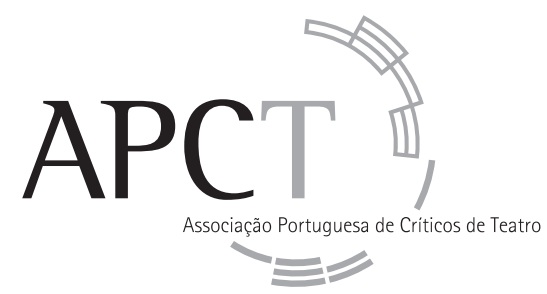

\begin{tabular}{c|l} 
Presidente honorário & Carlos Porto \\
Direcção & $\begin{array}{l}\text { Maria Helena Serôdio } \\
\text { Paulo Eduardo Carvalho } \\
\text { Rui Cintra }\end{array}$ \\
Assembleia Geral & $\begin{array}{l}\text { Luiz Francisco Rebello } \\
\text { Fernando Midões }\end{array}$ \\
Conselho Fiscal & $\begin{array}{l}\text { Ana Isabel Vasconcelos } \\
\text { Maria João Caetano } \\
\text { Mónica Guerreiro }\end{array}$
\end{tabular}

ESTATUTOS $\quad$ Capitulo Primeiro (Da Associação e dos seus fins)

Art. $2 .{ }^{\circ}$

A Associação tem por objectivo:

Dignificar, estruturar e responsabilizar a actividade crítica relativa à teoria e prática do teatro, entendendo-se por actividade crítica não só a crítica de espectáculos, mas também tudo aquilo que diga respeito à informação, reflexão e teorização no campo das artes performativas.

\section{Colaboração com Sinais de cena}

A revista está aberta à participação de quem deseje colaborar enviando artigos que julgue corresponderem aos objectivos da publicação e às modalidades enunciadas pelas rubricas existentes. A consulta do sítio da APCT na Internet (www.apcteatro.org) e o contacto por correio electrónico (geral@apcteatro.org ou estudos.teatro@fl.ul.pt) são indispensáveis para conhecer as normas de apresentação dos artigos (dimensão, aspecto gráfico, citações, referências bibliográficas, ilustrações, etc.).

\section{ASSINATURA}

Desejo subscrever os números 5 e 6 da revista Sinais de cena (correspondentes a Junho e Dezembro de 2006), no valor total de 22,00 a beneficiando assim de um desconto sobre o preço de venda ao público.

Fora do país: Europa 24,00 a / Fora da Europa 26,00 a.

Nome:

Morada:

Lódigo postal: $\quad$ Pais:

Endereço electrónico:

\begin{tabular}{|l|l|} 
Forma de pagamento: $\quad \square$ Vale postal $\quad \square$ Cheque $n^{\circ}$. & Banco
\end{tabular}

Preencha e envie este cupão (ou fotocópia do mesmo) para:

Data: 


\section{ERRATA}

Por lapso, na Sinais de cena, n. ${ }^{\circ}$ 3, p. 111, o desenho de Ramada Curto é atribuído a Roberto Nobre, quando o seu autor é Amarelhe. 
